\title{
Interestingness in Attribute-Oriented Induction (AOI): Multiple-Level Rule Generation
}

\author{
Maybin K. Muyeba and John A. Keane \\ Department of Computation, UMIST, Manchester, M60 1QD, UK \\ muyeba, jak@co.umist.ac.uk
}

\begin{abstract}
Attribute-Oriented Induction $(A O I)$ is a data mining technique that produces simplified descriptive patterns. Classical $A O I$ uses a predictive strategy to determine distinct values of an attribute but generalises attributes indiscriminately i.e. the value 'ANY' is replaced like any other value without restrictions. $A O I$ only produces interesting rules by using interior concepts of attribute hierarchies. The COMPARE algorithm that integrates predictive and lookahead methods and of order complexity $O(n p)$, where $n$ and $p$ are input and generalised tuples respectively, is introduced. The latter method determines distinct values of attribute clusters and greatest number of attribute values with a 'common parent' (except parent 'ANY'). When generating rules, a rough set approach to eliminate redundant attributes is used leading to more interesting multiple-level rules with fewer 'ANY' values than classical $A O I$.
\end{abstract}

\section{Introduction}

Attribute-Oriented Induction $(A O I)[1]$ is a data mining technique that produces descriptive patterns by generalisation. Each attribute has a predefined concept hierarchy often referred to as domain knowledge. Concept hierarchy values (specifically interior concepts as shown in figure 1) are used repeatedly to replace low-level attribute values and generate a prime relation. Attributes that do not have concept hierarchies or posses a large number of distinct values (e.g. keys to relations) are dropped except in the key-preserving AOI [2]. The number of allowed attributes and tuples in the final table is controlled by attribute and rule thresholds $T_{\mathrm{a}}$ and $T_{\mathrm{r}}$ respectively. The end result is a final generalised relation or rule table of descriptive patterns. Rules produced in this way can use preserved keys to perform efficient data queries. For example, a rule describing American cars with low mileage can be used to query specific properties like engine size, type of steering etc from the database. Generally, leaf concepts and value 'ANY' are not interesting to the user as they represent known facts. The interesting values however lie in interior concepts of an attribute's concept hierarchy according to [3]. Classical AOI does not consider interestingness of the generated rules as the value 'ANY' or 'don't-care' is used without restrictions. 


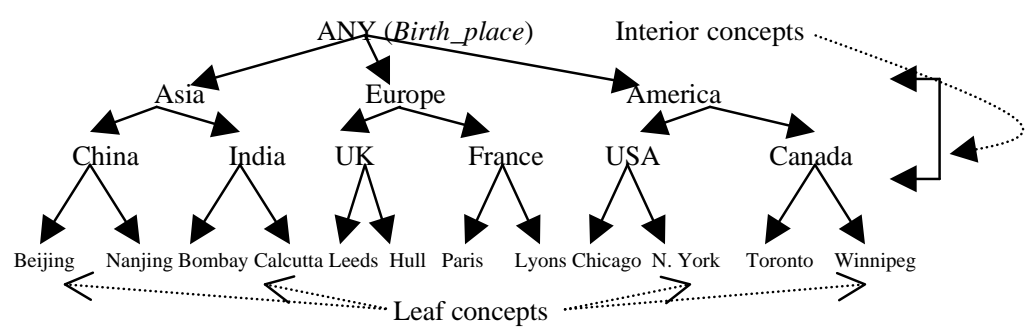

Fig. 1. Concept hierarchy for attribute 'Birth_place'

We propose an approach to obtain interesting multiple-level rules (rules with high and low-level concepts) and regulate the degree of the rule table by generalising clusters of attribute values with a 'similar' next high-level concept (a 'common parent'). A rough set approach is used to eliminate irrelevant attributes for rule generation [4].

The rest of the paper is organised as follows: section 2 presents related work; section 3 introduces concepts and terminologies; section 4 introduces the algorithm and analysis; section 5 shows an application of the approach using public domain data; section 6 presents conclusions and future work.

\section{Related Work}

Interestingness measures are either objective or subjective [5]. Objective approaches to foster interestingness in AOI can be categorised as lookahead and predictive [6]. The former are based on selecting an attribute for generalisation using heuristic measures based on the attribute's concept hierarchy structure [8]. Predictive strategies use thresholds [4] or predetermine the interestingness potential of interior concepts of an attribute's hierarchy. The rough set approach is used to determine dependencies between attributes. In, classification, information gain is used to choose an attribute to use as a root of the classification tree [9]. This results in correctly classified trees. Our approach uses distinct attribute values to choose an attribute and generalise clusters of values for the attribute to produce multiple-level rules [7].

\section{Terminology and Definitions}

Suppose a database has $m$ attributes and $n$ tuples. Assume that a concept hierarchy $\mathrm{H}_{\mathrm{i}}$ is defined for each attribute $\mathrm{A}_{\mathrm{i}}, \mathrm{i}=2 . . m$ and a prime relation of $p$ tuples exists.

Definition 3.1 A Concept hierarchy $H_{i}$ of $A_{i}$ is a poset (partially ordered set) $(H, \prec)$ where $H_{i}$ is a finite set of concepts and $\prec$ is a partial order on $H_{i}$.

Definition 3.2. An attribute $A_{i}$ is generalisable if there exists a concept hierarchy for the attribute (i.e. there are higher level concepts which subsume the given attribute values). Otherwise it is nongeneralisable. 
Definition 3.3 A concept $y$ of attribute $\mathrm{A}_{\mathrm{i}}$ is the nearest ancestor of concept $x$ if $x, y \in$ $\mathrm{H}_{\mathrm{i}}$ with $x \prec y, x \neq y$, and there is no other concept $z \in \mathrm{H}_{\mathrm{i}}$ such that $x \prec z$ and $z \prec y$.

Definition 3.4 A concept y of attribute $\mathrm{A}_{\mathrm{i}}$ is an interior concept of $\mathrm{H}_{\mathrm{i}}$ if $y$ is a non-leaf concept and $\mathrm{y} \neq$ 'ANY'.

Definition 3.5 Two concept values $\mathrm{a}_{\mathrm{r}}, \mathrm{a}_{\mathrm{s}} \in \mathrm{A}_{\mathrm{i}}$ have a 'common parent' $p \in \mathrm{H}_{\mathrm{i}}$ if $p$ is the nearest ancestor of $a_{r}$ and $a_{s}$.

Definition 3.6 A key $t_{p}\left(A_{i}\right)$ of a tuple $t_{p}$ is the first numeric attribute value, $\mathrm{i}=1, p<=n$.

Definition 3.7 A characteristic rule [7] is a rule whose left hand side is the query condition of the target data and the right hand side is a conjunction of generalised (attribute, value) pairs.

Definition 3.8 Two tuples $\mathbf{t}_{\mathrm{p}}$ and $\mathbf{t}_{\mathrm{q}}$ are equivalent if $\mathbf{t}_{\mathrm{p}}\left(\mathrm{A}_{\mathrm{i}}\right)=\mathbf{t}_{\mathrm{q}}\left(\mathrm{A}_{\mathrm{i}}\right), \mathrm{i} \neq 1, \mathrm{i}=2, . ., \mathrm{m}$.

Definition 3.9 A merge of two tuples $\mathbf{t}_{\mathrm{p}}$ and $\mathbf{t}_{\mathrm{q}}$ occurs by determining their equivalence, incrementing the count of total equivalent tuples by one and deleting one tuple.

The first task the algorithm in the next section deals with is maintaining interestingness through the $A O I$ generalisation process. After reducing the complexity of the data by $A O I$, the second part which is rule generation, introduces a rough set approach. Rules are then represented as decision rules. When decision rules are generated, rules redundancies and rule inconsistencies may arise. Our proposed algorithm inherently solves this problem by the nature of the generalisation process (see application example). Definitions and detail theory of decision rules, rule redundancy and inconsistencies are given in [4].

\section{Common Parent Rule Algorithm (COMPARE)}

The COMmon PArent RulE (COMPARE) algorithm performs AOI primitives as follows:

1. Retrieve the input and generalise each tuple during input so that no tuple has leaf concepts at rule generation stage except for attributes with a concept hierarchy depth 1 of 1 . This also reduces the number of tuples in memory to a small relation.

2. An attribute threshold $T_{a}$ and an evaluation function ${ }^{2}$ for choosing the next attribute for generalisation are used. For each chosen attribute, all attribute values with a 'common parent' (excluding 'ANY') are grouped together and counted. The group with the highest count is generalised until thresholds are reached.

3. Rule generation only considers reduction of number of tuples by further generalisation of selected attribute values and controlled by a rule threshold $\mathrm{Tr}$. Significant values ${ }^{\mathrm{B}}$ are used to eliminate less significant attributes by starting with tuples differing in one attribute value. This approach, like in [4], ensures that we remain with non-redundant attributes for rule generation.

\footnotetext{
${ }^{1}$ Depth of root node is zero and any other node is 1 more than the depth of its parent

${ }^{2}$ The function $d_{\text {weigh }} / t_{\text {weight }}$ is used in [4]

${ }^{3}$ The chi-square statistic $\mathrm{X}^{2}$
} 


\subsection{Analysis}

When an attribute $A_{i}$ is chosen for generalisation using the evaluation function, attribute values with a 'common parent' in the concept hierarchy $\mathrm{H}_{\mathrm{i}}$ are identified and grouped together. When $k$ similar attribute values are encountered (i.e. they have a 'common parent'), $k$ keys are inserted in a $(p+c) x(p+c)$ array and a count of the flags (denoting each flag as ' $\mathrm{z}$ ') representing 'a similar value encounter' is recorded, where $c$ allows for all ' $z$ ' flags and is small. The number of distinct values in each group is evaluated taking all ' $z$ ' flags into account and the group with the highest value is a candidate for further generalisation. This process is repeated with other groups until the evaluation function is satisfied using threshold $\boldsymbol{T}_{a}$.

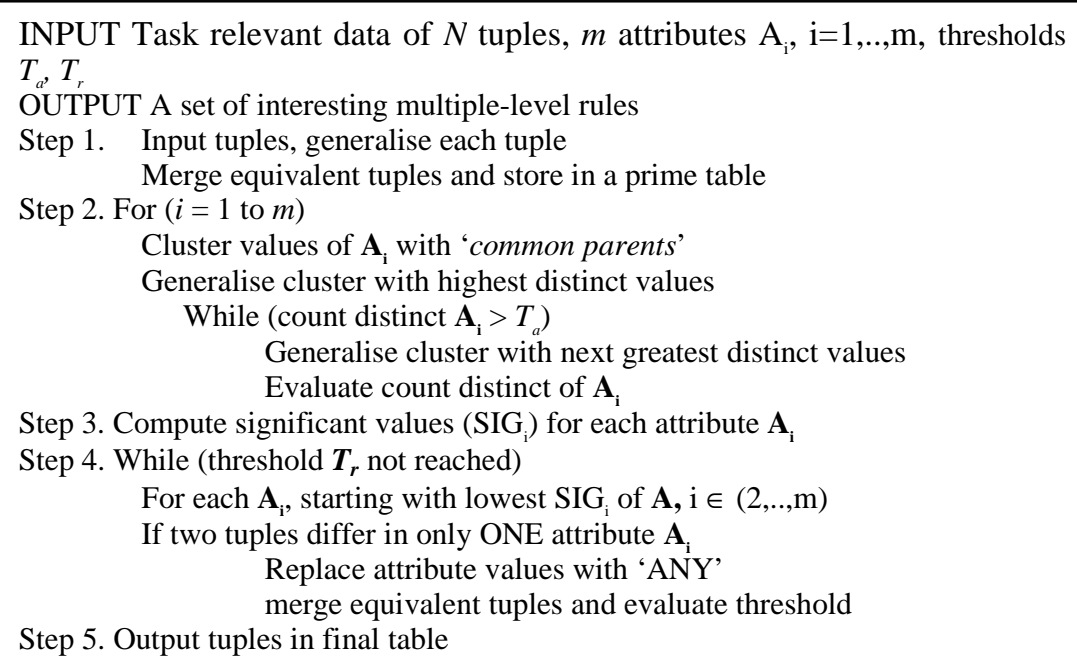

Fig. 2. The COMPARE algorithm

The complexity of the algorithm in figure 2 is evaluated as follows: To input $n$ tuples to a generalised prime relation is $O(n p)$ [2] and finding distinct values for each attribute $\mathrm{A}_{i}$ is $O(m), 0<i \leq m$, for $m$ attributes and $p$ generalised values [6]. For $h$ clusters of $\mathrm{A}_{i}$ where $C_{j i}=\left\{C_{1 \mathrm{i}}, . ., C_{\mathrm{hi}}\right\},\left|C_{j i}\right|<p / m, \forall j=1, \ldots, h$, i.e. the size of clusters $C_{j i}$ are not too different for each attribute. Inserting 'similar value encounter' in the $(p+c) x(p+c)$ array is less than $O\left(p^{2}\right)$ and negligible. Assuming the cardinality of each corresponding cluster is the same for each attribute (i.e. $\left|\mathrm{C}_{11}\right|=\left|\mathrm{C}_{12}\right|=\left|\mathrm{C}_{13}\right|$ etc except for concept distributions), then the number of tuples is expressed as

$$
\sum_{\mathrm{i}=1 \mathrm{j}=1}^{\mathrm{m} \mathrm{h}} \sum\left(\left|C_{j i}\right|\right)=p .
$$

After choosing attribute $\mathrm{A}_{i}$, to find common parent for attribute values in $\mathrm{j}^{\text {th }}$ cluster $\mathrm{C}_{j i}$ for $k$ concepts and generalising, the complexity is $O\left(k \mid C_{j i}\right)$. For $h$ clusters of $m$ 
attributes, the complexity is $O\left(k m h \mid C_{j i}\right)$ in the worst case, where each $\mathrm{C}_{i j}$ is generalised for small $k$ and $m$. Since $\left|C_{j i}\right|<\mathrm{p} / \mathrm{m}, h m\left|C_{j i}\right|=p, \forall_{\mathrm{j}, \mathrm{i}}$ and therefore the order complexity is $\mathrm{O}(\mathrm{kp})$ or just $\mathrm{O}(p)$.

The complexity of the algorithm by using attribute thresholds is $O(n p)+O(m)+$ $O(p)=O(n p)$. To merge the prime relation using least significant values for $m$ attributes and inserting in a final table of $q$ tuples, the complexity is $O\left(\mathrm{pqm}^{2}\right)$. Thus, if we say $p=n_{i}$, and $q=n_{o}$ as in [6], we have $O\left(m^{2} n_{i} n_{o}\right)$. Thus we have order complexity $O(n p)+O(p)+O\left(m^{2} p q\right)$. For small $p$ and $q$ in large databases, the complexity is reduced to $O(n p)$.

\subsection{Example Application}

Table 1. Car Information

\begin{tabular}{|c|c|c|c|c|c|c|c|c|c|c|}
\hline $\begin{array}{l}\text { Cno } \\
\end{array}$ & Model & Fuel & Disp & Weight & 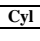 & Power & Turbo & Comp & Tran & Mileage \\
\hline & Ford Escort & $\begin{array}{l}\mathrm{EFI} \\
\mathrm{FFI}\end{array}$ & $\begin{array}{l}\text { Medium } \\
\text { vedium }\end{array}$ & 876 & 6 & $\begin{array}{l}\text { High } \\
H \text { Hiog }\end{array}$ & $\begin{array}{l}\text { Yes } \\
\text { No }\end{array}$ & High & $\begin{array}{l}\text { auto } \\
\text { amponat }\end{array}$ & $\begin{array}{l}\text { Medium } \\
\text { Medium }\end{array}$ \\
\hline & $\begin{array}{l}\text { Dodge Shadow } \\
\text { Ford Festiva }\end{array}$ & $\begin{array}{l}\text { EFI } \\
\text { EFI }\end{array}$ & $\begin{array}{l}\text { Medium } \\
\text { Medium }\end{array}$ & $\begin{array}{l}\begin{array}{l}1100 \\
1589\end{array} \\
\end{array}$ & 6 & 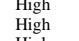 & $\begin{array}{l}\text { No } \\
\text { No }\end{array}$ & $\begin{array}{l}\text { Medium } \\
\text { High }\end{array}$ & $\begin{array}{l}\begin{array}{l}\text { manu } \\
\text { manu }\end{array} \\
\text { mant }\end{array}$ & $\begin{array}{l}\text { Medium } \\
\text { Medium }\end{array}$ \\
\hline & $\begin{array}{l}\text { Chevrolet Corvette } \\
\text { Dodge Stealth }\end{array}$ & $\begin{array}{l}\text { EFI } \\
\text { EFI }\end{array}$ & $\begin{array}{l}\text { Medium } \\
\text { Medium }\end{array}$ & $\begin{array}{l}987 \\
1096\end{array}$ & $\begin{array}{l}6 \\
6 \\
6\end{array}$ & 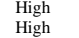 & $\begin{array}{l}\text { No } \\
\text { No }\end{array}$ & $\begin{array}{l}\text { Mediu } \\
\text { Hight }\end{array}$ & 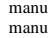 & $\begin{array}{l}\text { Medium } \\
\text { Medium }\end{array}$ \\
\hline & Ford Probe & EFI & & 867 & 6 & High & no & Mediu & manu & Medium \\
\hline 8 & $\begin{array}{l}\text { Ford Mustang } \\
\text { Dodge Daytona }\end{array}$ & $\begin{array}{l}\text { EFI } \\
\text { EFI }\end{array}$ & $\begin{array}{l}\text { Medium } \\
\text { Medium }\end{array}$ & $\begin{array}{l}1197 \\
798\end{array}$ & $\begin{array}{l}6 \\
6 \\
\end{array}$ & $\begin{array}{l}\text { High } \\
\text { High }\end{array}$ & $\begin{array}{l}\text { no } \\
\text { yes }\end{array}$ & $\begin{array}{l}\text { Iigh } \\
\text { High }\end{array}$ & $\begin{array}{l}\substack{\text { manuu } \\
\text { manu }} \\
\text { mant }\end{array}$ & $\begin{array}{l}\text { Medium } \\
\text { High }\end{array}$ \\
\hline & $\begin{array}{l}\text { Chrysler Le Baron } \\
\text { Dodge Srite }\end{array}$ & & $\begin{array}{l}\text { Medium } \\
\text { Medium }\end{array}$ & $\begin{array}{l}1056 \\
1557\end{array}$ & ${ }_{6}^{4}$ & $\begin{array}{l}\text { Mediu } \\
\text { nith }\end{array}$ & no & $\begin{array}{l}\text { Medium } \\
\text { Yediume }\end{array}$ & manu & Medium \\
\hline & $\begin{array}{l}\text { Dogecspinc } \\
\text { Honda Civic }\end{array}$ & 2-BBL & $\begin{array}{l}\text { Medulum } \\
\text { Small }\end{array}$ & $\begin{array}{l}1587 \\
786\end{array}$ & 4 & $\begin{array}{l}\text { High } \\
\text { Low }\end{array}$ & $\begin{array}{c}\text { no } \\
\text { no } \\
-10\end{array}$ & High & $\begin{array}{l}\begin{array}{l}\text { manu } \\
\text { manu }\end{array} \\
\text { mats }\end{array}$ & $\begin{array}{l}\text { Low } \\
\text { High }\end{array}$ \\
\hline 12 & $\begin{array}{l}\text { Ford Escort } \\
\text { Ford Tempo }\end{array}$ & $\begin{array}{l}2-B B L \\
2 \text {-BBL }\end{array}$ & 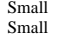 & $\begin{array}{l}1098 \\
1118\end{array}$ & $\begin{array}{l}4 \\
4\end{array}$ & Low & no & $\begin{array}{l}\text { High } \\
\text { Hiog }\end{array}$ & manu & $\begin{array}{l}\text { Medium } \\
\text { Medium }\end{array}$ \\
\hline & Toyota Corolla & & Small & 1023 & & Low & no & & manu & High \\
\hline $\begin{array}{l}16 \\
16\end{array}$ & $\begin{array}{l}\text { Madada } 233 \\
\text { Dodge Daytona }\end{array}$ & $\begin{array}{l}\text { EFI } \\
\text { EFI }\end{array}$ & $\begin{array}{l}\text { Medium } \\
\text { Medium }\end{array}$ & $\begin{array}{l}698 \\
1123\end{array}$ & $4_{4}^{4}$ & $\begin{array}{c}\text { Meddum } \\
\text { Medum }\end{array}$ & $\begin{array}{c}\text { no } \\
\text { no } \\
\text { nat }\end{array}$ & $\begin{array}{c}\text { Medium } \\
\text { M }\end{array}$ & $\begin{array}{l}\begin{array}{l}\text { manu } \\
\text { manu }\end{array} \\
\text { mant }\end{array}$ & $\begin{array}{l}\text { High } \\
\text { Medium }\end{array}$ \\
\hline 17 & $\begin{array}{l}\text { Honda Prelude } \\
\text {. }\end{array}$ & $\mathrm{EFI}$ & Small & 1094 & 4 & High & yes & High & manu & High \\
\hline 19 & Chevrolet Corsica & EFI & Medium & 980 & ${ }_{4}^{4}$ & High & $\begin{array}{l}\text { yes } \\
\text { yes }\end{array}$ & Medium & $\begin{array}{l}\text { manu } \\
\text { manu }\end{array}$ & Medium \\
\hline 20 & $\begin{array}{l}\text { Chevrolet Beretta } \\
\text { Covrolet Cavalier }\end{array}$ & $\begin{array}{l}\text { EFI } \\
\text { EFI }\end{array}$ & $\begin{array}{l}\text { Medium } \\
\text { Medium }\end{array}$ & $\begin{array}{l}1600 \\
1002\end{array}$ & $\begin{array}{l}6 \\
6 \\
\end{array}$ & $\begin{array}{l}\text { High } \\
\text { High }\end{array}$ & no & $\begin{array}{l}\text { Medium } \\
\text { Medium }\end{array}$ & $\begin{array}{l}\text { auto } \\
\text { auto }\end{array}$ & Low \\
\hline 23 & Chrysler Le Baron & EFI & $\begin{array}{l}\text { Medium } \\
\text { Smoll }\end{array}$ & 1098 & & $\begin{array}{l}\text { High } \\
\text { Hedium }\end{array}$ & no & Medium & auto & Medium \\
\hline 24 & Chevrolet Corsica & $\begin{array}{l}\mathrm{EFI} \\
\mathrm{EFI}\end{array}$ & Small & $\begin{array}{l}1080 \\
980 \\
-10\end{array}$ & $4_{4}^{4}$ & $\begin{array}{l}\text { Medumum } \\
\text { Medium }\end{array}$ & $\begin{array}{l}\text { no } \\
\text { no }\end{array}$ & 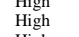 & $\begin{array}{l}\text { manu } \\
\text { manu }\end{array}$ & $\begin{array}{l}\text { Hign } \\
\text { High }\end{array}$ \\
\hline & & & & & & & & & & \\
\hline
\end{tabular}

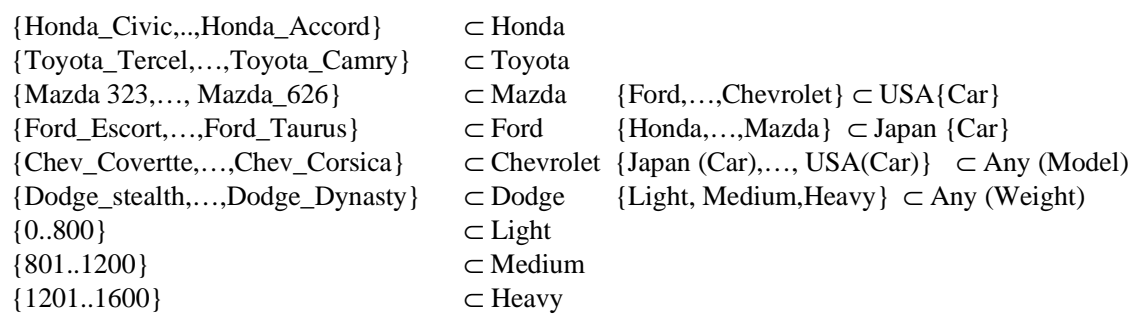

Fig. 3. A concept hierarchy for Table 1

Consider a collection of car information in Table 1 and its associated concept hierarchy shown in figure 3. From the tables, the attributes 'Fuel', 'Disp', 'Cyl', 'Power', 'Turbo', 'Comp', 'Tran' and 'Mileage' have at most 3 distinct values and their concept hierarchies are not given. If we choose to investigate characteristics of 
cars that determine mileage from the given data, then mileage will be a decision attribute or target class and all other attributes will be a conjunction of generalised attribute value pairs. This eliminates the attributes 'Fuel', 'Disp', 'Cyl' and 'Turbo' by analogy and expert knowledge. Another attribute ' $\mathrm{Cno}$ ' for car number to act as a key for each tuple as defined earlier is introduced.

\subsection{Results}

A Generalised Car Information System is first obtained as shown in table 2.

Table 2. A table generated from COMPARE algorithm (18 tuples)

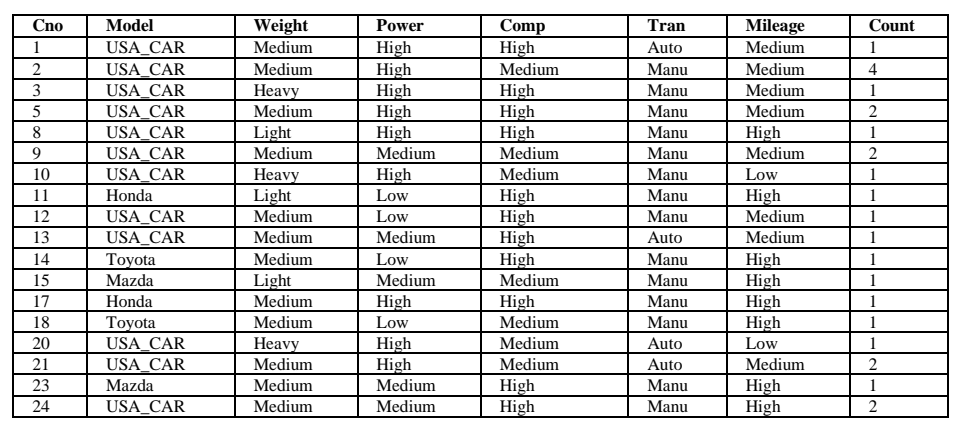

Table 3. Significant values for attributes

\begin{tabular}{|l|l|l|l|}
\hline Attribute & $\chi^{2}$ & Attribute & $\chi^{2}$ \\
\hline Weight & 17.54 & Tran & 4.53 \\
\hline Model & 12.86 & Comp & 3.84 \\
\hline Disp & 7.08 & Fuel & 0.63 \\
\hline Cyl & 5.94 & Turbo & 0.63 \\
\hline Power & 5.68 & & \\
\hline
\end{tabular}

Attribute and rule thresholds of 3 and 9 were used to compare the results obtained in [6]. Significant values for attributes in table 2 are shown in table 3. Applying the COMPARE algorithm generates table 4. The values 'ANY' are represented by '-'. After attribute thresholds are satisfied, rule thresholds need to be satisfied by further processing of table 4 . Table 5 shows the generated table using the user-defined rule threshold $\boldsymbol{T}_{\mathrm{r}}=9$.

Table 4. A table after merging tuples differing by one attribute (12 tuples)

\begin{tabular}{|l|l|l|l|l|l|l|l|}
\hline Cno & Model & Weight & Power & Comp & Tran & Mileage & Count \\
\hline 1 & USA_CAR & Medium & High & - & - & Medium & 8 \\
\hline 3 & US__CAR & Heavy & High & High & Manu & Medium & 1 \\
\hline 6 & USA_CAR & Meium & Medium & - & Manu & Medium & 4 \\
\hline 8 & USACAR & - & Medium & High & Manu & High & 3 \\
\hline 10 & USA_CAR & Heavy & Low & Medium & Manu & Low & 1 \\
\hline 11 & Honda & Light & Low & High & Manu & High & 1 \\
\hline 13 & USA_CAR & Medium & Medium & Hgh & Auto & Medium & 1 \\
\hline 14 & Toyota & Medium & Low & - & Manu & High & 2 \\
\hline 15 & Mazda & Light & Medium & Medium & Manu & High & 1 \\
\hline 17 & Honda & Medium & High & High & Manu & High & 1 \\
\hline 20 & USA_CAR & Heavy & High & Medium & Auto & Low & 1 \\
\hline 23 & Mazda & Medium & Medium & High & Manu & High & 1 \\
\hline
\end{tabular}


Table 5. Final Table ( 8 tuples)

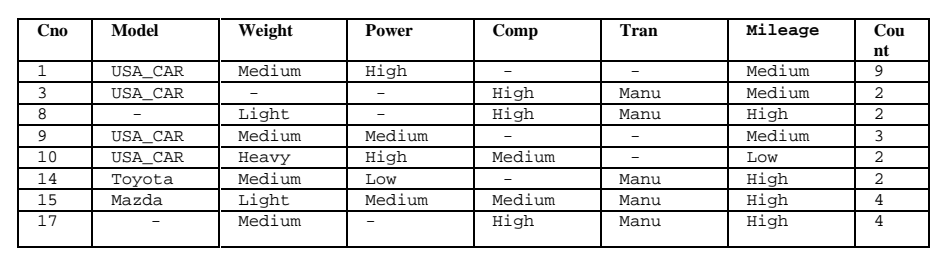

Notice that for attribute 'Model' in table 5, the concepts 'Toyota' and 'Mazda' are less general than 'USA_CAR' or 'JAPAN_CAR'. With a rule threshold, no rule inconsistencies arise as the number of rules would be few. Arguably, a small rule threshold means producing more general rules that may not be interesting. Rule 1 (first row of table 5) shows that about 32\% of cars having 'Medium' weight, 'High' power and 'Medium' mileage are USA cars. If any of the less significant attributes like 'Tran', 'Comp', or 'Power' were removed, no rule inconsistencies arise or even when all three are removed together. The rules with keys 1 and 9 are logically included in the rule with key 3 when 'Comp' and 'Tran' are generalised to 'ANY'. If attributes 'Tran', 'Comp', 'Model' and 'Power' are removed, rules with keys 1 and 9 are inconsistent with rules with keys 14 and 17 i.e. ,if (weight=medium) then (mileage=Medium) " is inconsistent with ,if (weight=medium) then (mileage=High) “ respectively. So we keep the attribute 'Model'. Similarly, if 'Power', 'Model' and 'Tran' were removed, the rule ,if (weight=medium) then (mileage=Medium) “ with keys 1 and 9 is inconsistent with rule ,if (weight=medium) then (mileage=High) “ with key 14 unless 'Model' or 'Power' is kept and so on.

Table 6. Final Table ( 9 tuples)

\begin{tabular}{|l|l|l|l|l|l|}
\hline Model & Weight & Power & Comp & Tran & Mileage \\
\hline- & Heavy & - & Medium & - & Low \\
\hline USA_CAR & Medium & High & - & - & Medium \\
\hline USA_CAR & Medium & - & Medium & - & Medium \\
\hline- & Medium & - & - & Auto & Medium \\
\hline USA_CAR & - & Low & - & - & Medium \\
\hline- & Heavy & - & High & - & Medium \\
\hline- & - & Medium & High & Manu & High \\
\hline Japan & - & - & - & - & High \\
\hline- & Light & - & - & - & High \\
\hline
\end{tabular}

Using this approach, fewer or no inconsistent rules are generated unless most attributes are dropped. This is because step 2 of the algorithm clusters attribute values with common parents making tuples less equivalent. Analysing table 6 from [6] shows that attribute 'Model' has no values 'Toyota' and 'Mazda' as they have been over generalised to value 'Japan'. Also, more significant attributes like 'Model' and 'Weight' (table 5) have larger numbers of 'non-ANY' attribute values than those in table 6. This comparison is also true for less significant attributes. In general, the number of 'don't-care' or 'ANY' values in table 5 (12 of them) as compared to those in table 6 (26 of them) shows how cautiously the algorithm generalises the data by delaying replacement of 'ANY'. This is advantageous in preserving interestingness of the rules. 


\section{Conclusion}

We have presented the COMPARE algorithm of complexity $\mathrm{O}(n p)$ that integrates predictive and lookahead strategies, by use of thresholds and 'common parent' respectively, for rule interestingness in AOI. Using these two approaches and the rough set approach for removing noisy data at rule generation, interesting multiplelevel rules are produced in AOI. Further work can be summarised as follows:

- Repeatedly check rule thresholds when merging. Both our approach and classical $A O I$ overlook this. For example, a rule threshold of 9 may produce 8 rules instead of 9 (see tables 5,6). In table 4, merging tuples with keys represented by key pairs $(1,6)$, $(8,23)$ reduces the tuples from 12 to 10 . The next merge is pair $(10,20)$ and the rule threshold of 9 is satisfied. Therefore, we need not merge the next pair $(11,17)$. In large databases, this would be important for preserving interestingness.

- By Integrating with relevant attribute selection [6] prior to mining and the interestingness approach presented, more interesting rules may be produced.

\section{References}

1. Han, J.; Cercone, N. and Cai, Y. 1991. „Attribute-Oriented Induction in Relational Databases" In G. Piatetsky-Shapiro and W. J. Frawley, editors, Knowledge Discovery in Databases, pp 213-228.

2. Muyeba, K. M., and Keane, J.A 1999. „Extending Attribute-Oriented Induction as a Key-Preserving Data Mining Method" In Proceedings of the Third European Conference on Principles of Data Mining and Knowledge Discovery (PKDD’99), Prague, Czech. Republic, pp 448-455.

3. Fudger, D. and Hamilton, H. 1993. „Heuristic Evaluation of Databases for Knowledge Discovery with DBLEARN" International Workshop on Rough Sets and Knowledge Discovery, Banff, Canada, pp 29-39.

4. Shan, N.; Howard, J. H. and Cercone, N. 1996. „GRG: Knowledge Discovery Using Information Generalisation, Information Reduction and Rule Generation" In International Journal of Artificial Intelligence tools, 5: (1\&2), pp 99-112.

5. Silberschatz, A. and Tuzhilin, A. 1995. „On subjective measures of Interestingness in Knowledge Discovery" In Proceedings of the First International Conference on Knowledge Discovery and Data Mining (KDD'95), Montreal, Canada, pp 275-281.

6. Barber, B. and Howard, H. J. 1997. „A Comparison of Attribute Selection Strategies for Attribute-Oriented Generalisation" In International Symposium on Methodologies for Intelligent Systems (ISMIS'97), Charlotte, NC, pp 106-116.

7. Yongiian, F. 1996. „Discovery of Multiple-level Rules from Large Databases“, Ph.D. thesis, Simon Fraser University, Canada.

8. Carter, C.L.; Hamilton, H. J. and Cercone, N. 1994. „The Software Architecture of DBLEARN“, Technical Report CS-94-04, University of Regina.

9. Quinlan, J. R. 1986. „Induction of decision trees“, Machine Learning, Vol. 1, pp 81-106. 